\title{
FERNANDES, Estevão R. “Existe índio gay?”: a colonização das sexualidades indígenas no Brasil. Curitiba: Editora Prismas, 2017. 245p.
}

\section{Carmen Lúcia Silva Lima}

\section{(2) OpenEdition Journals}

Edição electrónica

URL: http://journals.openedition.org/aa/4400

DOI: $10.4000 / a a .4400$

ISSN: 2357-738X

Editora

Programa de Pós-Graduação em Antropologia Social (UnB)

Edição impressa

Data de publição: 1 dezembro 2019

Paginação: 379-382

ISSN: 0102-4302

\section{Refêrencia eletrónica}

Carmen Lúcia Silva Lima, «FERNANDES, Estevão R. "Existe índio gay?": a colonização das sexualidades indígenas no Brasil. Curitiba: Editora Prismas, 2017. 245p.», Anuário Antropológico [Online], v.44 n.2 | 2019, posto online no dia 03 dezembro 2019, consultado o 27 abril 2021. URL: http://journals.openedition.org/aa/4400 ; DOl: https://doi.org/10.4000/aa.4400

\section{(c) $)(1)(9)$}

Anuário Antropológico is licensed under a Creative Commons Atribuição-Uso Não-Comercial-Proibição de realização de Obras Derivadas 4.0 International. 


\title{
FERNANDES, Estevão R. “Existe índio gay?”: a colonização das sexualidades indígenas no Brasil. Curitiba: Editora Prismas, 2017. 245p.
}

\author{
Carmen Lúcia Silva Lima \\ Universidade Federal do Piauí - Brasil
}

O livro aborda o processo de colonização da sexualidade indígena e reflete sobre o lugar que ela ocupa no empreendimento colonial. Reúne seis artigos de autoria de Estevão Fernandes, já publicados em periódicos, entre os quais parte da sua tese de doutorado, que também se encontra de forma resumida na obra Gay Indians in Brazil, publicada pela Springer em 2017, em parceria com a também antropóloga Bárbara Arisi. A reunião desses escritos em uma única produção permite aos leitores contemplarem inteiramente a contribuição do autor para o entendimento do tema abordado.

“Existe índio gay?”, a interrogação presente no título causa impacto, desperta o interesse de pesquisadores que se ocupam do estudo de populações indígenas e instiga a curiosidade do público em geral. Por meio dela, somos convidados a refletir sobre o tema, o que nos faz constatar que não há como apresentar uma resposta simples, fácil e única. A sexualidade humana é complexa demais para reflexões simplistas e de pouco fôlego. Para aumentar esta complexidade, a vasta literatura etnográfica produzida até o momento nos revela que os povos indígenas são bastante diversos em suas práticas e na produção de significados.

Fernandes responde afirmativamente à questão, mas adverte que o livro não é sobre índios gays. O que ele procura realizar é uma abordagem sobre a heterossexualização imposta aos indígenas através das instituições, paradigmas e dogmas do colonizador. Para desenvolver essa proposta, ele recorre a pesquisa documental, bibliográfica e trabalho de campo. Metodologicamente, a homossexualidade indígena é usada como uma categoria guarda-chuva que abriga todas práticas que não se enquadram no modelo hétero hegemônico. Desta forma, não há uma apreciação das diversas categorias que hoje constituem as identidades sexuais e de gênero, tais como lésbicas, bissexuais, transexuais, intersexuais e queer. Consequentemente, o "índio homosexual" é uma construção que emerge no universo de contato com o colonizador e em meio ao processo de subordinação, colonização, proletarização, cristianização, cientificização e racialização dos desejos e sexualidades dos indígenas. 
A obra considera as práticas de vários povos indígenas no Brasil desde a colonização, que foram associadas ao pecado, vício e patologia. $\mathrm{O}$ avanço do empreendimento colonial representou a imposição da visão de mundo religiosa, filosófica e científica, que impôs o sistema moral que estruturava a sociedade colonizadora. Isto impor tou no esvaziamento da identidade, na medida em que ensinou aos indígenas que sua cultura era indesejada, sua sociedade representava o atraso, seus afetos eram errados, o amor por eles praticado era pervertido e a sua religião era desprovida de fé. Foi, portanto, uma ação de disciplinamento que visava enquadrar no padrão e heterossexual do colonizador. Esse processo, vale ressaltar, extrapola a dominação política e econômica finalizada com a independência, pois vai além da relação estabelecida entre a metrópole e a colônia e transcende a estrutura administrativa que foi imposta.

O autor recorre à etnologia brasileira para apresentar referências sobre o fenômeno estudado, com a pretensão de mostrar um campo de estudo consolidado, o que pode ser questionado, pois como ele mesmo registra, as reflexões sobre a homossexualidade indígena são recentes, o tema tem sido pouco explorado no campo dos estudos interétnicos e das relações coloniais. Tudo isso representa um desafio para tornar essa questão um tema de investigação protuberante no campo de estudos das populações indígenas, caracterizado por uma vastidão de temas, abordagens e autores. Considerando a incursão histórica de longa duração e a diversidade de povos abordados, certamente uma das questões que emergem é a viabilidade de enquadrar na categoria guarda-chuva por ele escolhida as diversas práticas registradas desde o período colonial por cronistas, missionários, viajantes, historiadores e antropólogos. Lembrar que a categoria homossexual surge especificamente na Europa burguesa e moderna, no século XIX, complica ainda mais.

Para Fernandes, a visão europeia sobre a sexualidade indígena esteve em sintonia com outras imagens de selvageria, tais como o incesto, a corrupção, a inversão, o canibalismo, a poligamia, a embriaguez, a luxúria, a sodomia, a nudez, os bacanais e as lascívias. São todos vocábulos que compõem um mesmo campo semântico e que têm seu significado situado no projeto de colonização, que teve como um eixo estruturante a doutrina cristã. Os relatos abordados levam a constatar que o território era percebido como um espaço privilegiado para a ação do demônio, o que, do ponto de vista teológico, justificou a dominação dos indígenas que o habitavam. Uma vez que o corpo ameríndio era visto como um reflexo da natureza corrompida, era preciso dominá-lo, pois através dele se chegaria à intervenção na alma. $\mathrm{O}$ 
homem católico europeu, praticante de sexo monogâmico com a esposa para fins reprodutivos era o ideal a ser perseguido de acordo com o projeto cristão ibérico.

A política indigenista do período colonial até a proclamação da República é analisada, tendo como marcos o Diretório dos Índios de 1757, a Carta Régia de 1798 e o Regulamento das Missões de 1845. A finalidade desse procedimento é mostrar a relação que se estabelece entre o discurso civilizatório presente na legislação, o período de sua elaboração e as políticas de miscigenação, normalização do espaço indígena, as regras de casamento e catequese. Esta linha de argumentação é adotada devido à percepção de que a lei evidencia a representação da ordem social e da classe dominante. A referida legislação comprova, portanto, o ideal de civilização, raça e colonização, sendo responsável pela heterossexualização dos indígenas. Fernandes demonstra bastante fôlego e segue além do período citado, contemplando ações desenvolvidas no século XX, tais como a infligida pelo Conselho Nacional de Proteção aos Índios - CNPI, o Serviço de Proteção ao Índio - SPI, a Fundação Nacional do Índio - FUNAI e, mais recentemente, o Estatuto do Índio. Por meio desta explanação, ele mostra a persistência da obsessão de controle de todos os aspectos da vida indígena, o que inclui o corpo e a sexualidade vivenciada.

Raça, sexo e civilização estão inter-relacionados e situados no projeto de colonização dos indígenas, tendo implicações nos dias atuais. De acordo com o autor, foi dessa relação que brotou a noção de progresso e nação e a justificativa de incorporação desses povos ao sistema econômico predominante. Para ele, o colonialismo está presente e age nas brincadeiras, no preconceito, nas agressões e mortes de indígenas LGBT nas aldeias e fora delas. Por esta razão, ele escolheu abordar a homossexualidade indígena como um fenômeno político e não pelo viés particularista, pois quando um indígena se identifica como homossexual ou gay, ele é afetado pela carga pejorativa de preconceitos oriundos do processo colonial, bem como da cultura de homofobia do Brasil contemporâneo.

Embora a escolha do autor seja bastante válida, durante a leitura surgem, por inúmeras vezes, interrogações sobre a viabilidade de afirmações tão generalistas e sobre o impacto do particularismo presente nas etnografias que abordam os indígenas no Brasil. Essa vasta literatura que foi se constituindo ao longo do tempo quase sempre nos leva a concordar que as comparações são possíveis, mas cada caso é um caso.

Concluindo, acertadamente o autor assegura que a colonização sexual favoreceu ao predomínio do empreendimento colonial. Ciência, filosofia e religião forneceram o instrumental retórico para o funcionamento do aparato colonizador, que agiu 
especificamente na gestão cotidiana dos corpos e desejos indígenas. Neste processo merece destaque a percepção de que o uso que os indígenas fazia de seus corpos, afetos e do prazer era uma violação da natureza e/ou fruto de uma raça pervertida e condenada ao fracasso. Desta forma foi justificado o controle da intimidade através, por exemplo, do disciplinamento das formas de residência, de casamento, das práticas corporais e reprodução. A metáfora de rolo compressor certamente se aplica à ação do aparato estatal e religioso que historicamente vem sufocando os povos indígenas.

Recebido: 18/01/2019

Aprovado: 13/02/2019

Carmen Lúcia Silva Lima é doutora em Antropologia pela Universidade Federal de Pernambuco (UFPE). Professora do Departamento de Ciências Sociais e do Programa de Pós-graduação em Antropologia da Universidade Federal do Piauí (UFPI). Líder do Grupo de Pesquisas sobre Identidades Coletivas, Conhecimentos Tradicionais e Processos de Territorialização da UFPI e pesquisadora do Projeto Nova Cartografia Social da Amazônia (PNCSA). Editora Chefa da Revista EntreRios e membro da Comissão de Projeto Editorial da Associação Brasileira de Antropologia - ABA (Gestão 2017/2018). Realiza pesquisa entre populações indígenas, povos e comunidades tradicionais. ORCID: 0000-0002-2427-7069. Contato: carmensllucia@gmail.com 